\title{
Climate Change Index: A Proposed Methodology for Assessing Susceptibility to Future Climatic Extremes
}

\author{
Manyu Chang1, Claudine Dereczynski ${ }^{2}$, Marcos A. V. Freitas ${ }^{1}$, Sin Chan $\mathrm{Chou}^{3}$ \\ ${ }^{1}$ International Virtual Institute of Global Change (IVIG), COPPE-UFRJ, Rio de Janeiro, Brazil \\ ${ }^{2}$ Department of Meteorology, Federal University of Rio de Janeiro, Rio de Janeiro, Brazil \\ ${ }^{3}$ Center for Weather Forecasting and Climate Research, National Institute of Space Research, \\ Cachoeira Paulista, Brazil \\ Email: manyu@ivig.coppe.ufri.br
}

Received 3 June 2014; revised 1 July 2014; accepted 25 July 2014

Copyright (C) 2014 by authors and Scientific Research Publishing Inc.

This work is licensed under the Creative Commons Attribution International License (CC BY).

http://creativecommons.org/licenses/by/4.0/

(c) (i) Open Access

\section{Abstract}

A Climate Change Index (CCI) was designed to assess the degree of susceptibility to the climatic extremes projected for the future. Climate projections for the period 2041-2070 are extracted from the numerical integrations of INPE's Eta-HadCM3 model, using the SRES A1B emissions scenario. Five indicators were chosen to represent the climatic extremes: Total annual precipitation, precipitation on the days of heavy rain, the maximum number of consecutive dry days in the year and the annual mean maximum and mean minimum temperatures. The methodology was applied to the state of Paraná. The results point to a very strong warming in $99 \%$ of the municipalities, with temperature increases between 6 and 8 times greater than the variance observed in the present climate. On the other hand, projections of precipitation do not indicate major changes in relation to present behavior.

\section{Keywords}

Climate Extremes, Index, Climate Change

\section{Introduction}

The results of the Fifth Assessment Report (AR5) of the Intergovernmental Panel on Climate Change [1] for South America indicate that the number of cold days and nights has been decreasing and the number of warm days and nights has been increasing since 1950. Positive tendencies in the frequency of occurrence and duration 
of heat waves, as well as in the amount of rain associated with extreme events are observed in more areas than negative trends. Unfortunately such results are of medium confidence due to insufficient data and studies in the region. For North America, Central America, Europe and Mediterranean results are more conclusive and show with high confidence the unequivocal warming. According to the IPCC, the air temperature at the surface (ocean and continent) measured globally increased by $0.85^{\circ} \mathrm{C}$ over the period $1880-2012$.

In this paper, some of the indicators of climatic extremes presented by the IPCC are used to compose the proposed Climate Change Index (CCI) whose objective is to indicate the degree of future susceptibility to climatic extremes in a given region. The CCI, along with other indices of biophysical susceptibility and socioeconomic vulnerability is used to comprise the synthesized Vulnerability Index (VI) for climatic extremes [2]. The VI seeks to identify vulnerabilities to climatic extremes of different dimensions that make certain regions susceptible to the impacts of climate change, with possible future exacerbations beyond what is happening at present.

The methodology used to construct the CCI reflects in a great extend the methodology used in the report "Map of the Vulnerability of the People of the State of Rio de Janeiro to the Impacts of Climate Change upon Social, Health and Environmental Areas” authored by FIOCRUZ and SEA-RJ 2011 [3]. In this report mean values of air temperature and precipitation are used. The present research opted for five indicators of climatic extremes as opposed to averages, since studies have shown an amplification of extremes in recent decades, despite the fact that climatological mean values have suffered little change [4]. Moreover, changes in extremes, as pointed out by the [1], have a much bigger impact on society and ecosystems in general than the increase in average values [5]-[7].

The proposed methodology is applied to the state of Paraná, which was initiated by the study on the detection of climate change, considering indicators of climatic extremes from observational data from the Agronomic Institute of Paraná [8].

The methodology and data used to calculate the CCI are given in Section 2; the results of applying the methodology to the state of Paraná are presented in Section 3; and the conclusions in Section 4.

\section{Data and Methodology}

\subsection{Simulations from the Eta-HadCM3 Model}

The meteorological data for the calculation of indicators of climatic extremes used to construct the CCI are obtained from simulations from the Eta regional model with horizontal resolution of $40 \mathrm{~km}$ by $40 \mathrm{~km}$. The regional Eta model [9] was nested inside the HadCM3 global coupled model [10]. This downscaling of global model simulations of the HadCM3 Eta model for South America will be called Eta-HadCM3. For present climate conditions (1961-1990) the $\mathrm{CO}_{2}$ concentration was considered to be $330 \mathrm{ppm}$, and for the future (2041-2070) climate, the emission scenario from the A1B Special Report on Emission Scenarios was used-SRES [11]. Four integrations were made with the Eta-HadCM3, generated from perturbations of the physics of the HadCM3 model. Among these four runs two were used in this study, one member (or scenario) which showed the highest climate sensitivity at the end of the century, to be referred to here as "high", and another member which had the lowest climate sensitivity, to be called "low". The climate sensitivity is based on the change in global temperature. The use of these two runs was an attempt to span the possible variations that the HadCM3 model produced in its global simulations. According to [12], although the four runs all correspond to the A1B emission scenario, the projections of temperature increase resulting from each of the runs show similarities to increases characteristic of scenarios of low (B1) and high emission (A2 or A1FI).

Reference [13] evaluated the simulations of the Eta-HadCM3 model for South America and showed good agreement between the simulations of the present climate and the observational data, suggesting adequacy of the model for studies of climate change in South America.

Reference [12] evaluated the climate projections of the Eta-HadCM3 model for South America for the future climate. The projections indicate a strong warming (between $4{ }^{\circ} \mathrm{C}$ and $6^{\circ} \mathrm{C}$ ) on the South American continent and strong reductions of rainfall in Amazonia and Northeast Brazil (reaching up to $40 \%$ compared to the present). All model projections point to more intense changes after 2041, indicating a drier and warmer climate in the basins of the Amazon, São Francisco and Paraná rivers, with small changes in precipitation for the last of these.

The variables used for the calculation of indicators of climatic extremes-air temperature every 6 hours and daily precipitation - are extracted from each of the 216 gridpoints of the Eta-HadCM3 model simulations over Paraná, with each point covering $40 \times 40 \mathrm{~km}^{2}$ of the territory of this state, as shown in Figure 1 . 


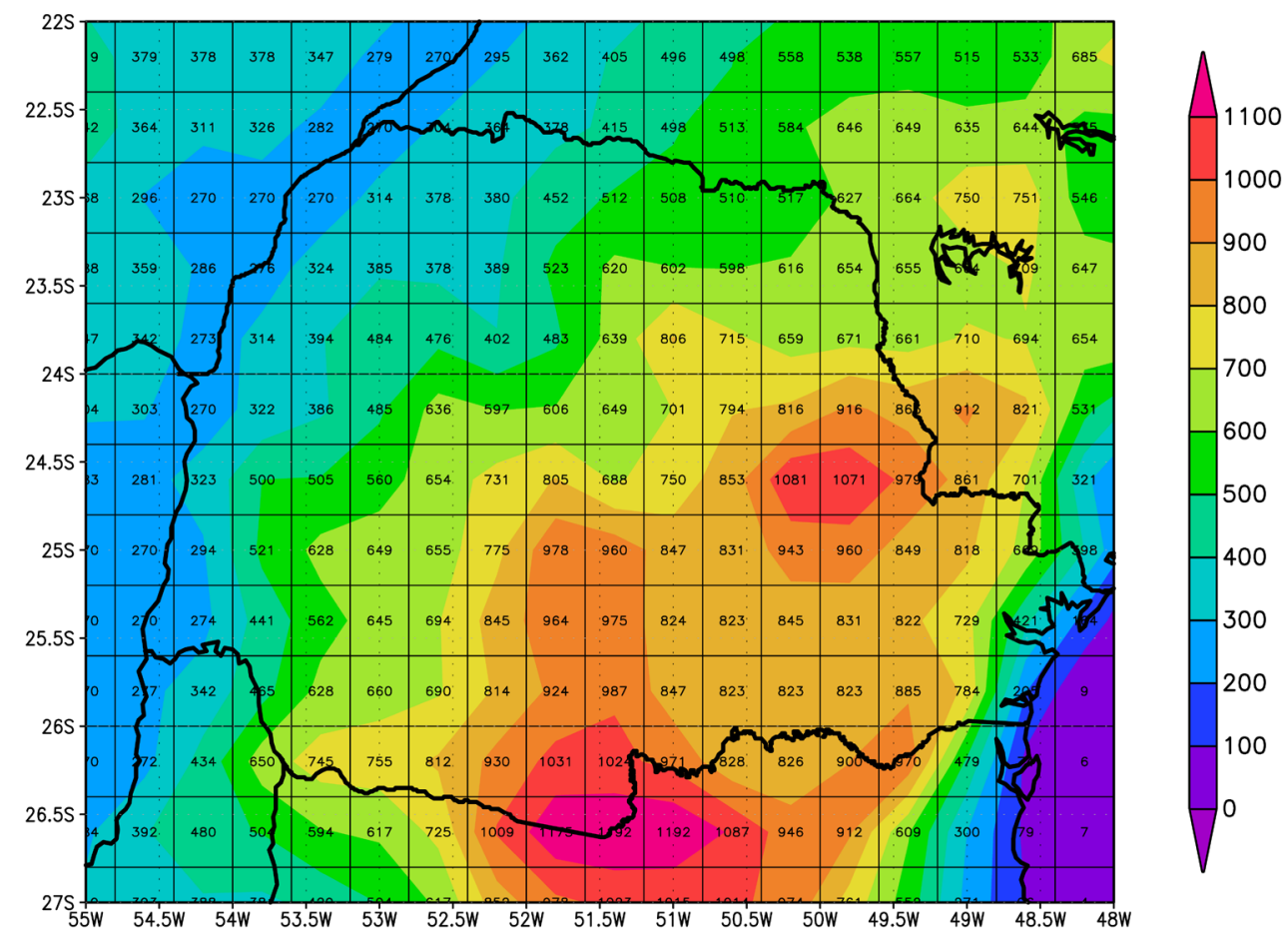

Figure 1. Model topography for the Eta-HadCM3 over the state of Paraná. The value shown in the center of each square represents the mean altitude $(\mathrm{m})$ in the model grid box.

For each model grid point, the indicators of climatic extremes are calculated for air temperature and precipitation from the present climate (1961-1990) and the future climate (2041-2070), for the "high" and "low" members. The choice of a future period at an intermediate distance between 2011 and 2099 is due to the fact that, a future that is too distant, such as 2100 , makes things more difficult for political decision-makers trying to grasp such a time span.

\subsection{Indicators of Climatic Extremes}

In the present research, five indicators of climatic extremes were selected from among those developed by the Expert Team on Climate Change Detection Monitoring and Indices (ETCCDMI), established by the Commission for Climatology of the World Meteorological Organization (WMO) and by the CLIVAR Climate Variability and Predictability Program to make viable a global analysis of climate extremes.

The five indicators of climatic extremes used in this research are: annual rainfall totals for rainy days, i.e., days when rainfall is greater than or equal to $1 \mathrm{~mm}$ (PRCPTOT, in $\mathrm{mm}$ ); total annual rainfall on days when rainfall is greater than that of the 95th percentile of the rainy days (R95p, in mm); maximum number of consecutive dry days for the year, that is, the days on which rainfall is less than $1 \mathrm{~mm}$ (CDD, in days) and annual mean maximum (TMAXmean) and minimum (TMINmean) temperatures, in degrees Celsius. These indicators are generated with the aid of the RClimdex program [14], formulated in Canada and designed specifically to calculate climatic extremes.

\subsection{Climatic Anomalies of Temperature and Precipitation}

The term "climatic anomaly" as used in this study is the absolute difference of the changes projected by the model for the future climate relative to its current climate. The outputs of the program RClimdex provide an annual value for each of the five indicators analyzed. Initially obtained for each grid point are the average values of the present (1961-1990) and future (2041-2070) period for PRCPTOT, R95p, CDD, TMAXmean and TMIN mean. Next we compute the "anomalies" as shown in Equation (1), obtaining the value of APRCPTOT, AR95p, ACDD, and ATMAXmean and ATMINmean at each grid point in the model. 


$$
\mathrm{AEXT}=\overline{\operatorname{EXT}}_{(2041-20170)}-\overline{\operatorname{EXT}}_{(1961-1990)}
$$

where AEXT represents the anomaly of the indicator of a climatic extreme and the bar represents the mean value of EXT in the period considered.

In addition to calculating climatic anomalies as described in Equation (1), we proceeded to normalize them, i.e., the "climatic anomalies" were also divided by their respective standard deviations (Equation (2)) calculated from the present climate. The "normalized climatic anomaly" (Equation (3)) reflects more effectively the impact of future climate change in relation to the present climate. In other words, the degree of stress due to a future climate change depends on the variability experienced in the present climate. This interpretation of "standard climatic anomaly" leads to the inference that the greater the present variability (standard deviation), the less the effect of stress felt due to future variation, because it is expected that populations and ecosystems would already be accustomed to the variability in a given phenomenon, and therefore are already adapted to it.

$$
\begin{gathered}
\mathrm{DP}_{\mathrm{EXT}}=\left(\frac{\sum_{j=1}^{N}\left(\mathrm{EXT}_{j}-\overline{\mathrm{EXT}}\right)^{2}}{N}\right)^{1 / 2} \\
\mathrm{AEXT}_{n}=\frac{\mathrm{AEXT}}{\mathrm{DP}_{\mathrm{EXT}}}
\end{gathered}
$$

where $N$ is the total number of years, EXT are the values of the indicators of climatic extremes (PRCPTOT, R95p, CDD, TMAXmean and TMINmean) for each year $(j), \mathrm{DP}_{\mathrm{EXT}}$ is the standard deviation of the indicator of climatic extreme and $\mathrm{AEXT}_{n}$ is the normalized anomaly of the indicator of the climatic extreme.

Despite the advantages of standardization as described above, the analyses related purely to "climatic anomalies" (without normalization) are maintained here in order to stress the absolute magnitude of the changes projected for the future (2041-2070) in relation to the present (1961-1990) for air temperature and precipitation.

\subsection{Normalized Climatic Anomalies}

After the calculation of the "normalized climatic anomalies" for each indicator of an extreme at each grid point in the state of Paraná, these are divided into classes. The division into classes considers the lowest and highest value of the "normalized anomalies" of the five indicators of extremes obtained at all model grid points for each of the two members, "high" and "low". For each of the classes a score is assigned ranging from 0 to 1 , with a score of 0 attributed to the smallest and 1 to the largest with respect to the standard deviation.

In order to obtain the indicators of normalized climatic extremes for each of the 399 municipalities in the state of Paraná, the Grid Analyst ArcGIS 10.1 program was used, with the aid of the Extract Value Grid with Polygon command. The polygon in this case is the geographic representation of each municipality that is superimposed on the contours resulting from the interpolation of the grid data. This process of "municipalization” generates for each municipality in Paraná a normalized anomaly indicator for each of the five chosen parameters.

The Climate Change Index (CCI) is represented by the highest score of the class of anomalies among the five indicators of climate extremes for the "high" and "low" members, as shown in Equation (4). This is achieved with the understanding that when one of the variables under analysis presents a significant climatic anomaly, be it temperature, precipitation or drought stress, this is sufficient to characterize the susceptibility to future climate change, so that the calculation of the average anomalies cannot mischaracterize the intensity of anomalies and underestimate important critical aspects.

$$
\mathrm{CCI}=\operatorname{MAX}-\operatorname{Nota}\left[\operatorname{APRCPTOT}_{n}, \operatorname{AR95p}_{n}, \operatorname{ATMAXmean}_{n}, \operatorname{ATMINmean}_{n}\right]
$$

\section{Results for the State of Paraná}

In this section the methodology proposed for the calculation of the CCI is presented for the state of Paraná. The results and maps obtained give indications of the anomalies of the climatic extremes in the state for the "high" member, projected for the period 2041-2070. Initially, the distribution of the anomalies of the climatic extremes associated with precipitation and air temperature is analyzed. 


\subsection{Spatial Distribution of the Extremes of Precipitation}

In Figures 2-4, the anomaly strips are shown for the indicators of climatic extremes of precipitation, which includes APRCPTOT, AR95P and ACDD, for the "high" member. It is noted on the maps of APRCPTOT and R95p a similar pattern of anomaly, with increased rainfall in almost the entire region studied, intensifying from north to south in the state. The total annual rainfall on wet days (PRCPTOT) projected from 2041 to 2070 (relative to 1961-1990) shows an average increase ranging from $15 \mathrm{~mm}$ in the north to $466 \mathrm{~mm}$ in the south, including the coast. In regard to ACDD higher values can be seen, indicating dry periods that are longer in the northeast but fall off towards the southwest coast of the state. In the northeast of the state it is projected for 20412070 an average increase of about 7 days in the duration of periods of consecutive dry days.

\subsection{Spatial Distribution of the Extremes of Temperature}

For the extremes of temperature (ATMAXmean and ATMINmean), a projection of warming throughout the state is noted, with the largest increases of temperature in the northeast, approximately $4^{\circ} \mathrm{C}$ in the "high" mem

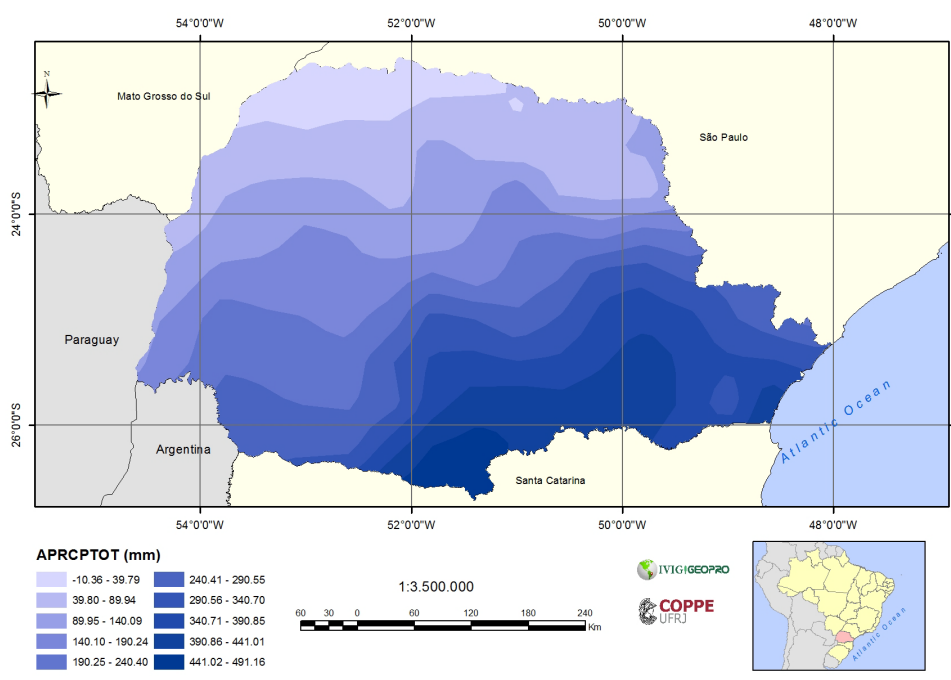

Figure 2. Spatial distribution in the state of Paraná of the APRCPTOT (mm) projected for 2041-2070 in the "high" member.

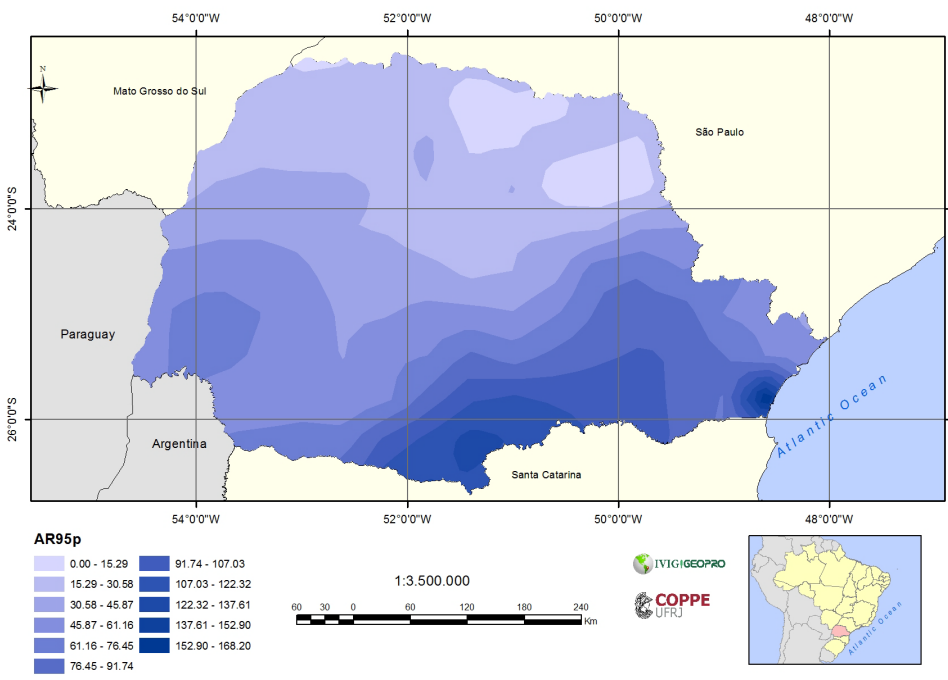

Figure 3. Spatial distribution in the state of Paraná of the AR95p (mm) projected for 2041-2070 in the "high" member. 
ber, decreasing in the direction of the coast. This indicates that the present-day rate of increase of TMAXmean and TMINmean, which is statistically significant at $+0.02^{\circ} \mathrm{C} /$ year [8], will be intensified in the future.

\subsection{Analysis of the CCI at the State Level}

In order to facilitate the interpretation of the CCI, the predominant anomalies were grouped into three categories: 1) precipitation anomaly, grouping the anomalies of APRCPTOT and AR95p; 2) anomaly of hydrologicstress, which is the same as the anomaly ACDD; and 3) temperature anomaly, composed of the maximum (ATMAXmean) and minimum (ATMINmean) temperature anomalies.

Table 1 shows the average for each indicator of extreme climate throughout the state of Paraná from its normalized anomalies. We note that with the normalization of extreme weather anomalies projected for 2041-2070, the prevailing anomaly happens to be, for the most part, related to extremes of temperature, with the minimum temperature $\left(\operatorname{ATMin}_{n}\right)$ having the greatest influence. The temperature anomaly $\left(\operatorname{ATMax}_{n}\right.$ and $\left.\operatorname{ATMin}_{n}\right)$ in the municipalities was significantly larger than all the weather extremes analyzed. For the "high" scenario the

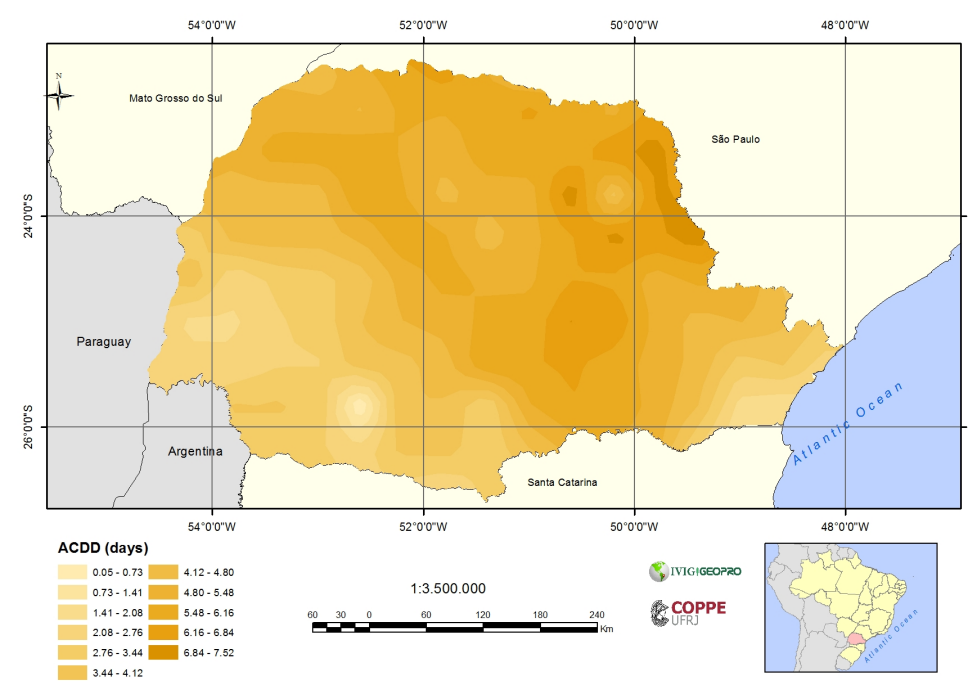

Figure 4. Spatial distribution in the state of Paraná of the ACDD (days) projected for 2041-2070 in the "high" member.

Table 1. Means of the indicators of climatic extremes and their respective standard deviations in the high and low members for the state of Paraná.

\begin{tabular}{|c|c|c|c|c|}
\hline $\begin{array}{l}\text { Indicator of } \\
\text { climatic extreme }\end{array}$ & member & $\begin{array}{l}\text { Mean of the standard deviations } \\
\text { (SD) for the period 1961-1900 }\end{array}$ & $\begin{array}{l}\text { Mean of the anomaly (A) of climatic extreme } \\
\text { projected for the period 2041-2070 }\end{array}$ & $\begin{array}{l}\text { Mean of the } \\
\text { normalized anomalies }\end{array}$ \\
\hline \multirow{2}{*}{ PRCPTOT (mm) } & high & 226 & 186 & 0.76 \\
\hline & low & 305 & 230 & 0.75 \\
\hline \multirow{2}{*}{ CDD (days) } & high & 5.7 & 4.49 & 0.81 \\
\hline & low & 8.1 & 0.91 & 0.09 \\
\hline \multirow{2}{*}{ R95p (mm) } & high & 138 & 45.8 & 0.33 \\
\hline & low & 166 & 46.3 & 0.29 \\
\hline \multirow{2}{*}{$\operatorname{TMax}\left({ }^{\circ} \mathrm{C}\right)$} & high & 0.59 & 3.25 & 5.57 \\
\hline & low & 0.89 & 1.88 & 2.22 \\
\hline \multirow{2}{*}{$\operatorname{TMin}\left({ }^{\circ} \mathrm{C}\right)$} & high & 0.48 & 3.25 & 6.79 \\
\hline & low & 0.48 & 2.2 & 4.68 \\
\hline
\end{tabular}


projected ATMINmean is 6.79 times larger than its standard deviation in the present climate, while all the mean precipitation anomalies, whether in the "high" or "low" scenario, had values below 1, indicating impacts of little relevance. In other words, the expected future precipitation variability is current already.

The distribution of the number of municipalities in Paraná in each score class is shown in Table 2, where it can be seen that even in the "low" scenario the scores are greater than 0.4 and in the "high" scenario $98 \%$ of the scores are concentrated between 0.8 and 1 .

The maps of the normalized anomalies of climatic extremes in the "high" member are shown in Figure 5, except for AR95 $_{n}$ and ATMINmean ${ }_{n}$ which were omitted because of no indications of large variations in their spatial patterns. ATMINmean ${ }_{n}$ values (figure not shown) are very high in almost the entire state, with scores in the class 0.8 - 1.0, except only around the municipality of Telêmaco Borba in the Serra do Cadeado, where the class is slightly lower, between 0.6 and 0.8. Regarding ATMAXmean ${ }_{n}$ (Figure 6), most of the municipalities show strong anomalies (scoring at 0.6 to 0.8 ), with a group of 16 municipalities in the far Central-South region showing very strong anomalies (score at 0.8 to 1 ).

With regard to the three indicators analyzed that characterize extremes precipitation, APRCPTOT $_{n}$,

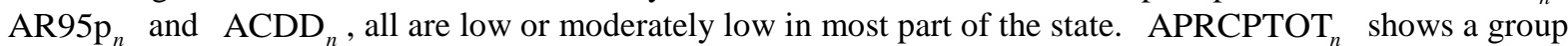
of municipalities with moderately low index, between 0.2 and 0.4, located in the Southeastern region and some municipalities in the far Southwest of the state (see Figure 7). AR95p showed low intensity (score 0 to 0.2 ). As

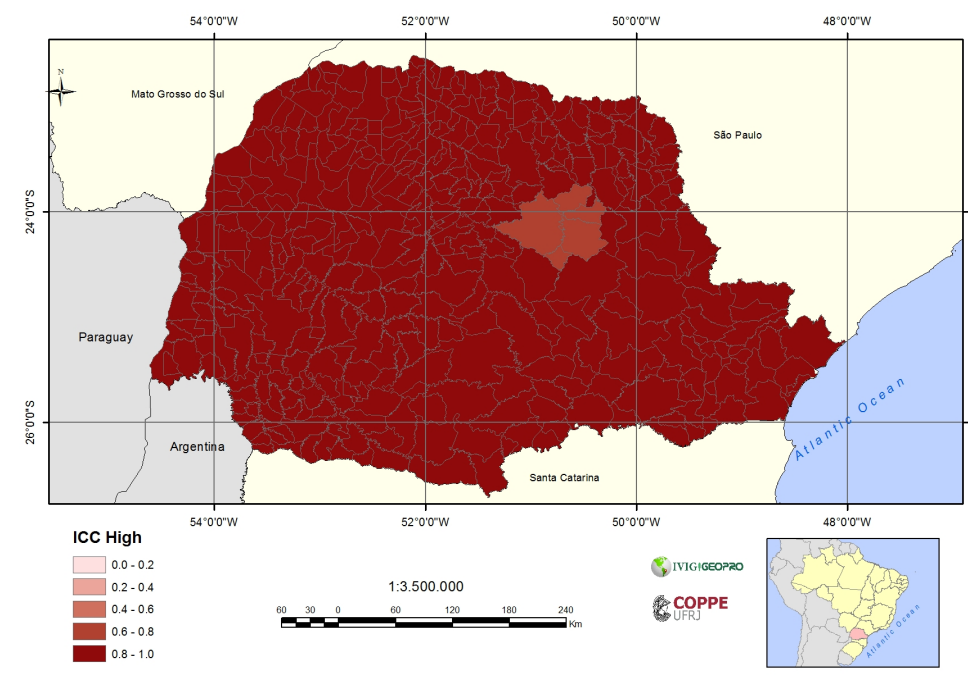

Figure 5. Map of Climate Change Index in the "high” member in the state of Paraná.

Table 2. Means of the indicators of climatic extremes and their respective standard deviations in the high and low members for the state of Paraná.

\begin{tabular}{|c|c|c|c|}
\hline \multirow{3}{*}{$\begin{array}{l}\text { Score classes } \\
\text { of the } \mathrm{CCI}_{n}\end{array}$} & \multirow{3}{*}{ Multiples of standard deviation } & \multicolumn{2}{|c|}{ CCI } \\
\hline & & "high" & "low" \\
\hline & & \multicolumn{2}{|c|}{ No. of municipalities } \\
\hline$\geq 0$ to $\leq 0.2$ & -0.7 to 1.7 & 0 & 0 \\
\hline$>0.2$ to $\leq 0.4$ & 1.7 to 3.7 & 0 & 0 \\
\hline$>0.4$ to $\leq 0.6$ & 3.7 to 5.0 & 0 & 182 \\
\hline$>0.6$ to $\leq 0.8$ & 5.0 to 6.6 & 5 & 217 \\
\hline$>0.8$ to $\leq 1.0$ & 6.6 to 8.2 & 394 & 0 \\
\hline Total & & 399 & 399 \\
\hline
\end{tabular}


for $\mathrm{ACDD}_{n}$ this also showed a group of municipalities with moderately low index in the class from 0.2 to 0.4 , also located in the Eastern region of the state, excluding the municipalities at the coast at the Serra do Mar (Figure 8).

Superposing the maps of $\mathrm{ACDD}_{n}$ (Figure 8) and $\mathrm{APRCPTOT}_{n}$ (Figure 7) it can be observed that there is a subgroup of 47 municipalities in the south/southeast that is prominent in changing the distribution of precipitation, showing an increase in PRCPTOT as well as in CDD, albeit with moderately low intensity (Figure 9). In other words, these municipalities will experience a major shift in the distribution of rainfall, with greatest total annual rainfall and longer dry periods in the future (Figure 9). The municipalities have values of APRCPTOT between 0.4 and 0.6 and ACDD between 0.2 and 0.4 .

Table 3 groups the municipalities by class of scores of standardized climatic extremes.

It appears that in general, the effects of anomalies related to rain ( $\mathrm{APRCPTOT}_{n}, \mathrm{AR95}_{n}$, and $\mathrm{ACDD}_{n}$ ) are of little importance in most municipalities, concentrated as they are in the lowest class of scores (i.e., 0 to 0.2 ) of low intensity. This is due to the fact that the projected magnitude of the anomaly of precipitation extremes fits

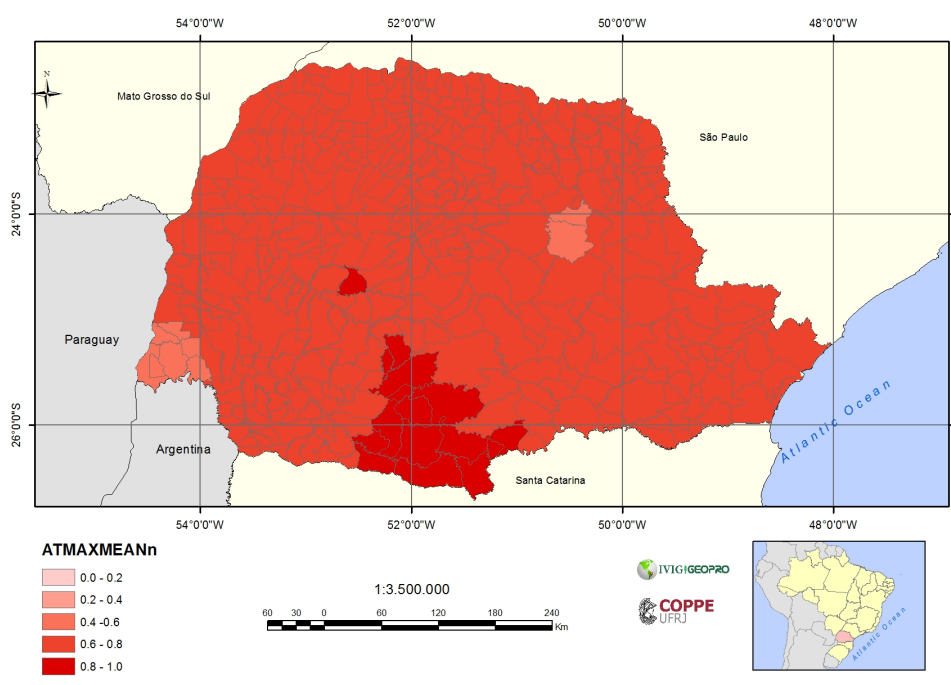

Figure 6. Projection of the ATMAXmean ${ }_{n}$ indicator by municipality in the state of Paraná in the "high" member.

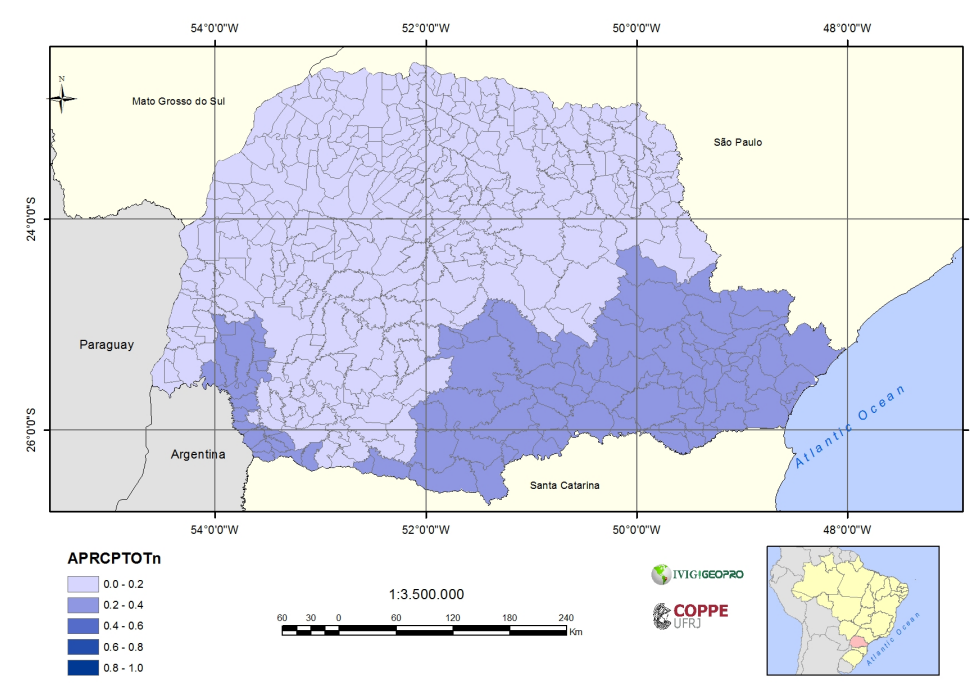

Figure 7. Projection of the normalized $\mathrm{APRCPTOT}_{n}$ indicator by municipality in the state of Paraná in the "high" member. 


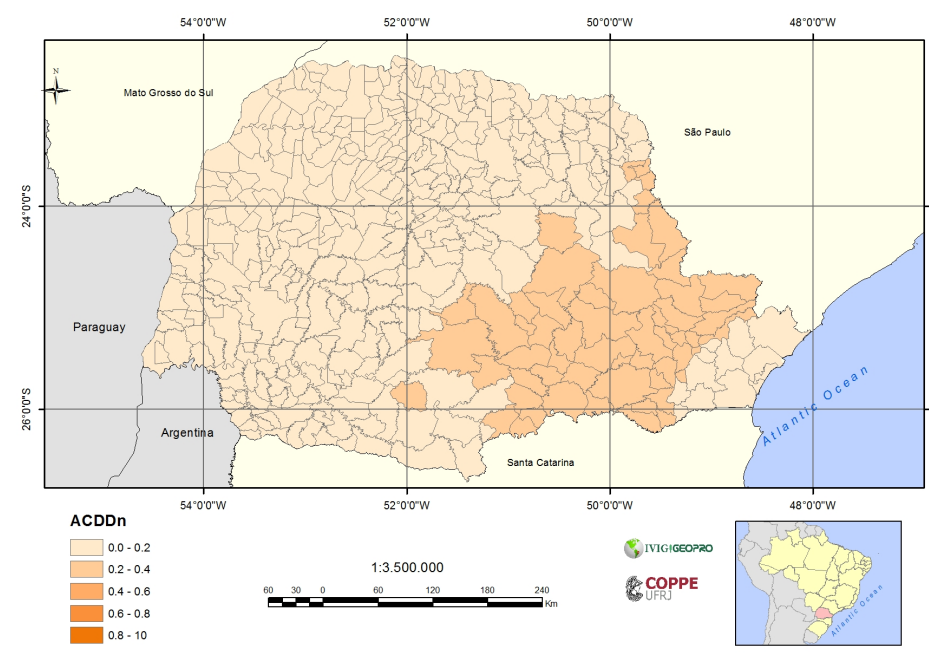

Figure 8. Projection of the normalized $\mathrm{ACDD}_{n}$ indicators by municipality in the state of Paraná in the member "high".

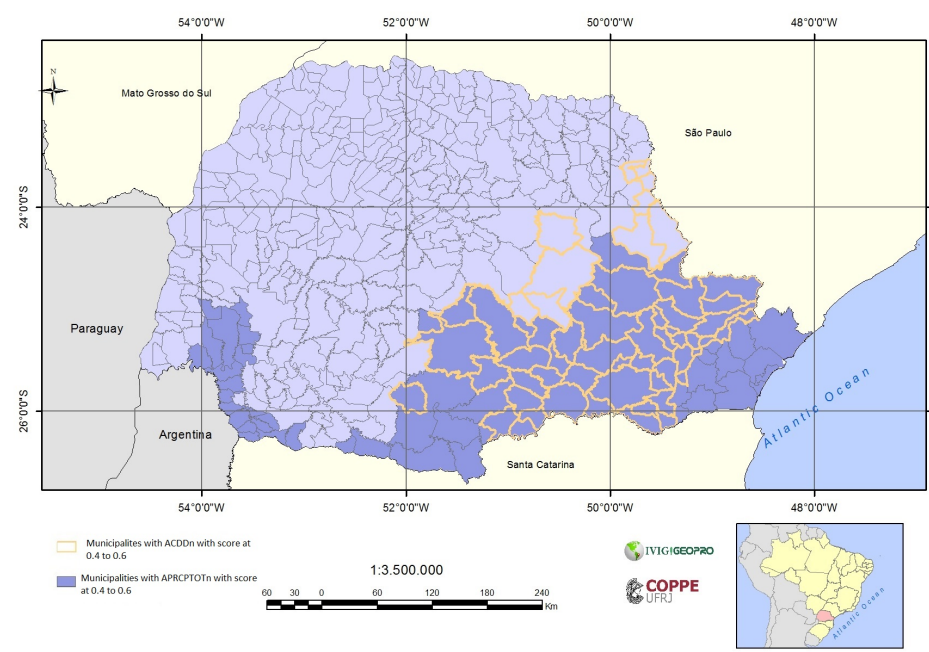

Figure 9. Municipalities with a projected increase of APRCPTOT, highlighted in blue, and of ACDD, outlined in orange.

Table 3. Number of municipalities by classes of normalized climatic extremes in the municipalities of the state of Paraná.

\begin{tabular}{|c|c|c|c|c|c|c|c|c|c|c|}
\hline \multirow{4}{*}{$\begin{array}{c}\text { Classes of scores of } \\
\text { normalized climatic } \\
\text { extremes }\end{array}$} & \multicolumn{10}{|c|}{ Indicators of anomalies of normalized climatic extremes } \\
\hline & \multicolumn{2}{|c|}{ APRCPTOT $_{n}$} & \multicolumn{2}{|c|}{$\mathrm{AP95p}_{n}$} & \multicolumn{2}{|c|}{$\mathrm{ACDD}_{n}$} & \multicolumn{2}{|c|}{$\operatorname{ATMax}_{n}$} & \multicolumn{2}{|c|}{$\operatorname{ATMin}_{n}$} \\
\hline & high & low & high & low & high & low & high & low & high & low \\
\hline & \multicolumn{10}{|c|}{ Number of municipalities } \\
\hline$\geq 0$ to $\leq 0.2$ & 308 & 357 & 399 & 399 & 342 & 399 & 0 & 0 & 0 & 0 \\
\hline$>0.2$ to $\leq 0.4$ & 91 & 42 & 0 & 0 & 57 & 0 & 0 & 394 & 0 & 0 \\
\hline$>0.4$ to $\leq 0.6$ & 0 & 0 & 0 & 0 & 0 & 0 & 9 & 5 & 0 & 182 \\
\hline$>0.6$ to $\leq 0.8$ & 0 & 0 & 0 & 0 & 0 & 0 & 374 & 0 & 5 & 217 \\
\hline$>0.8$ to $\leq 1.0$ & 0 & 0 & 0 & 0 & 0 & 0 & 16 & 0 & 394 & 0 \\
\hline Total & 399 & 399 & 399 & 399 & 399 & 399 & 399 & 399 & 399 & 399 \\
\hline
\end{tabular}


within the respective standard deviation of the precipitation extreme of the present climate.

Table 3 shows that the greatest susceptibility to future climate change will most likely fall on the minimum temperature, with 394 municipalities (99\%) having a very intense anomaly ( ATMin $_{n}$ in the "high" member) with maximum score between 0.8 and 1 , corresponding to an increase in the minimum temperature of 6 to 8 times the present-day standard deviation of minimum temperature.

The second largest anomaly is very likely to be the maximum temperature (also in the high member) where 16 municipalities have a very intense anomaly, with maximum score from 0.8 to 1 and 374 municipalities (94\%) characterized as intense, with a relatively high score, between 0.6 and 0.8 , which corresponds to a maximum temperature increase of 5 to 6 times the standard deviation of maximum temperature experienced at present.

It should be emphasized that it was established in the methodology of the CCI that if the municipality exhibits only one of the indicators of elevated climatic anomaly, this is sufficient to characterize it as susceptible to a future climatic anomaly. Consequently, it is concluded that virtually all municipalities in the state will be susceptible to climate change due to their susceptibility to anomalies of maximum and minimum temperatures prevailing in the case of high sensitivity to emissions of greenhouse gases from the A1B scenario.

\subsection{Analysis of Radar Charts of CCI}

The Climatic Change Index (CCI) is calculated for each municipality, where the analysis of the five climate extreme indicators jointly makes apparent the profile of the intensity of the projected anomalies. Figure 10 below is an example of a "radar" chart analysis for the municipality of União da Vitória as an illustration of this kind of visualization.

The municipality of União da Vitória is situated in the Central South of the State and, as already mentioned, is part of the group of municipalities with high $\mathrm{APRCPTOT}_{n}$ (moderately low, score $=0.26$, while at the same time there is an increase in ACDD, also moderately low in the "high" scenario $\left(\operatorname{ACDD}_{n}\right.$ "high", score $\left.=0.21\right)$. However, what stands out most for the municipality is the high intensity of the impact of the temperature anomaly in the "high" member. União da Vitória is one of the municipalities of the group most impacted in the high member with CCI "high" above 0.85 and CCI "low" equal to 0.63. In the "high" member, the impact appears very intense for both the minimum temperature $\left(\operatorname{ATMin}_{n}\right.$ "high", score $\left.=0.85\right)$ and for the maximum temperature $\left(\right.$ ATMax $_{n}$ "high", score $=0.81$ ). The score ATMin $_{n}$ "high" of 0.85 represents an anomaly of about six times the standard deviation of the present-day minimum temperature.

\section{Municipality of União da Vitória}

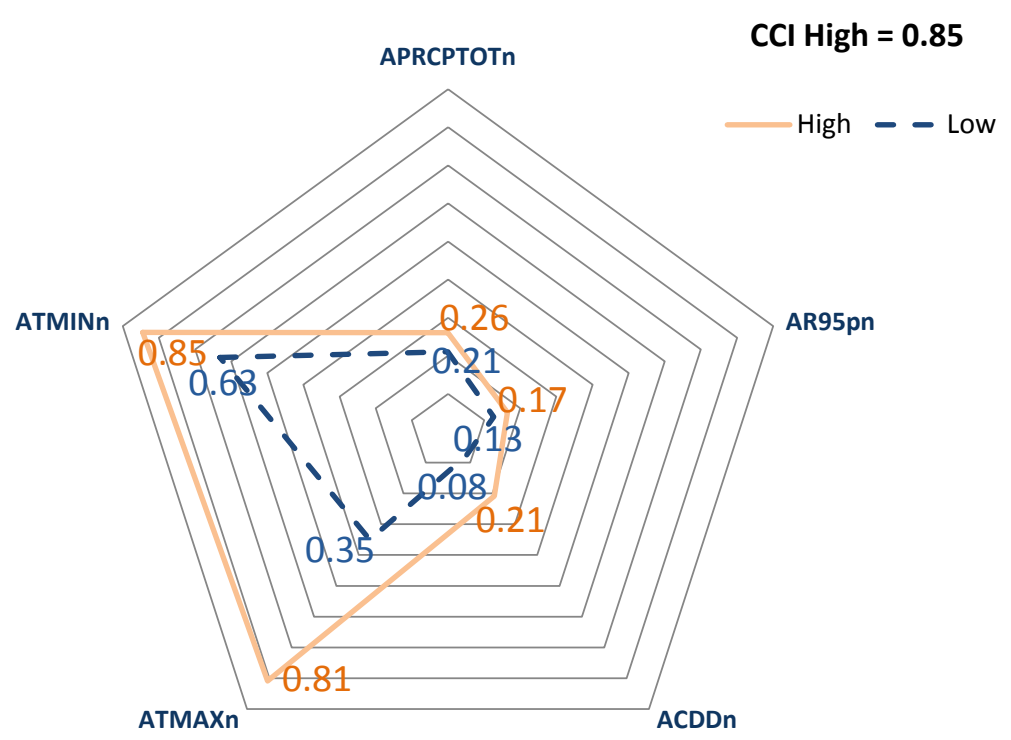

Figure 10. Radar Chart of the CCI for "high" and "low" members for the municipality of União da Vitória. 


\section{Conclusions}

In this paper we propose the use of a Climate Change Index (CCI) to assess the degree of susceptibility of a region to future climate extremes associated with the air temperature and precipitation. The advantage of this index is the possibility of synthesizing various extreme climatic indicators into a single index in a standardized way.

The methodology used to calculate the CCI is based on projections of indicators of climate extremes for a future period of two climatic scenarios (low and high emission) normalized in relation to their values in the present climate. The indicators of climatic extremes used are: total annual precipitation for days with rain, i.e., days when rainfall is equal to or greater than $1 \mathrm{~mm}$ (PRCPTOT, in $\mathrm{mm}$ ); total annual rainfall on the days when rainfall is greater than the 95th percentile of the rainy days (R95p, in mm); maximum number of consecutive dry days in the year, or days in which precipitation is less than $1 \mathrm{~mm}$ (CDD, in days); and annual averages of maximum (TMAXmean) and minimum (TMINmean) temperatures, in degrees Celsius. The methodology was applied to the state of Paraná from regionalized Eta-HadCM3 projections for the present (1961-1990) and future (2041-2070).

The results show an alleged increase in PRCPTOT for the period 2041-2070 as compared to the period 1961-1990, referred as the present climate by the RCM, that is projected to range from $25 \mathrm{~mm}$ in the northern part of the state to $465 \mathrm{~mm}$ in the south. Likewise, R95p will also increase in the future, following the same spatial pattern as PRCPTOT. On the other hand, an increase in CDD is projected, which means longer dry periods. This shows that if the projections prove accurate, then in the decades of 2041-2070 rainfall will be poorly distributed, with stronger and/or more frequent intense rainfall events and longer dry periods.

Analysis of the CCI makes clear that differences of projected extreme rainfall (total rainfall, heavy rain and water stress) are insignificant in view of the differences of projected extreme temperatures, since the change in future precipitation falls within the range of present variability. Conversely, the differences of projected extreme temperatures (both minimum and maximum) are likely to range between 2 to 7 times greater than the present variations.

In terms of comparison between the two members, the indicators of climatic extremes in the "high" member are in general stronger than those in the "low" member, with a larger number of municipalities with increased vulnerability in the "high" member, in the A1B emission scenario.

In terms of location of climate vulnerability within the state, practically all of the state in the "high" member, is found to be in the class with the highest score ( $\mathrm{CCI}>0.8$ ), which means very intense susceptibility, due to the increase projected in minimum temperatures.

These inferences, although preliminary, give indications of the need for preventive actions necessary over the medium and long term, by municipal and state authorities, such as the adaptation of crops, infrastructure, buildings, and changing of practices and behaviors to cope with projected climatic anomalies.

Large strides are being made in the improvement of global and regional models, with increasing accurate results for mapping climate sensitivity and vulnerability.

Likewise, in methodological terms, the indicators of climatic extremes selected for the calculation of the CCI can be adjusted to better represent future climate sensitivities to be faced in different states.

\section{References}

[1] IPCC (2013) Climate Change 2013: The Physical Science Basis. Contribution of Working Group I to the Fifth Assessment Report of the Intergovernmental Panel on Climate Change. Cambridge University Press, Cambridge and New York, in Press.

[2] Chang, M.Y. (2013) Estudo de Vulnerabilidade a Extremos Climáticos no Estado do Paraná. http://www.ivig.coppe.ufrj.br/ivig/Paginas/outras-publicacoes.aspx

[3] Barata, M.M.L. and Confalonieri, U.C. (2011) Mapa de Vulnerabilidade da População do Estado de Rio de Janeiro aos Impactos das Mudanças Climáticas nas Áreas Social, da Saúde e Ambiente. Relatório 4, SEA—RJ/FIOCRUZ, Rio de Janeiro.

[4] Alexander, L.V., et al. (2006) Global Observed Changes in Daily Climate Extremes of Temperature and Precipitation. Journal of Geophysical Research, 111, 1-22. http://dx.doi.org/10.1029/2005JD006290

[5] Easterling, D., Meehl, G., Parmesan, C., Changnon, S., Karl, T. and Mearns, L. (2000) Climate Extremes: Observations, Modeling and Impacts. Science, 289, 2068-2074. http://dx.doi.org/10.1126/science.289.5487.2068 
[6] Meehl, G., et al. (2000) An Introduction to Trends in Extreme Weather and Climate Events: Observations, Socioeconomic Impacts, Terrestrial Ecological Impacts and Model Projections. Bulletin of the American Meteorological Society, 81, 413-416. http://dx.doi.org/10.1175/1520-0477(2000)081<0413:AITTIE>2.3.CO;2

[7] Frich, P., et al. (2002) Observed Coherent Changes in Climatic Extremes during the Second Half of the Twentieth Century. Climate Research, 19, 193-212. http://dx.doi.org/10.3354/cr019193

[8] Silva, W.L., et al. (2013) Tendências Observadas em Indicadores de Extremos Climáticos de Temperatura e Precipitação no Estado do Paraná. Revista Brasileira de Meteorologia, in Press.

[9] Mesinger, F., et al. (2012) An Upgraded Version of the Eta Model. Meteorology and Atmospheric Physics, 116, 63-79. http://dx.doi.org/10.1007/s00703-012-0182-z

[10] Gordon, C., et al. (2000) Simulation of SST, Sea Ice Extents and Ocean Heat Transport in a Version of the Hadley Centre Coupled Model without Flux Adjustments. Climate Dynamics, 16, 147-168. http://dx.doi.org/10.1007/s003820050010

[11] Nakicenovic, N., et al. (2000) Special Report on Emission Scenarios. Cambridge University Press, Cambridge.

[12] Marengo, J.A., et al. (2012) Development of Regional Future Climate Change Scenarios in South America Using the Eta CPTEC/HadCM3 Climate Change Projections: Climatology and Regional Analyses for the Amazon, São Francisco and the Parana River Basins. Climate Dynamics, 38, 1829-1848. http://dx.doi.org/10.1007/s00382-011-1155-5

[13] Chou, S.C., et al. (2012) Downscaling of South America Present Climate Driven by 4-Member HadCM3 Runs. Climate Dynamics, 38, 635-653. http://dx.doi.org/10.1007/s00382-011-1002-8

[14] Zhang, X. and Yang, F. (2004) RClimDex (1.0)_User Manual. Climate Research Branch Environment Canada Downsview, Ontario. 
Scientific Research Publishing (SCIRP) is one of the largest Open Access journal publishers. It is currently publishing more than 200 open access, online, peer-reviewed journals covering a wide range of academic disciplines. SCIRP serves the worldwide academic communities and contributes to the progress and application of science with its publication.

Other selected journals from SCIRP are listed as below. Submit your manuscript to us via either submit@scirp.org or Online Submission Portal.
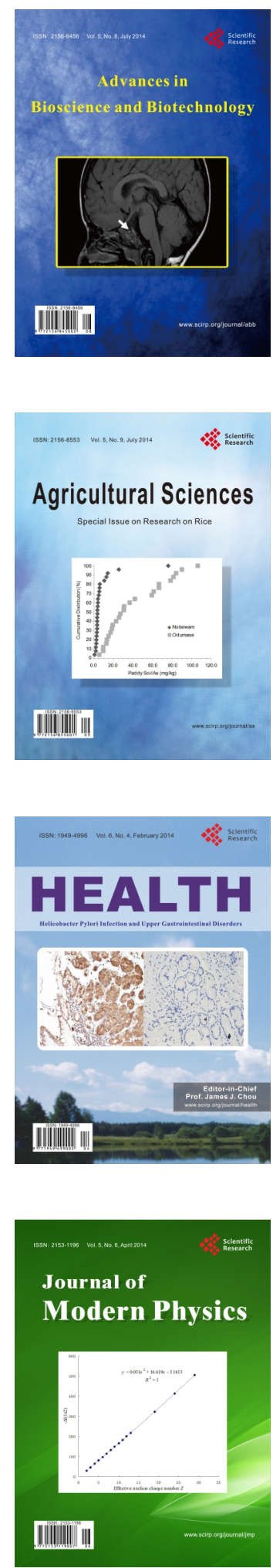
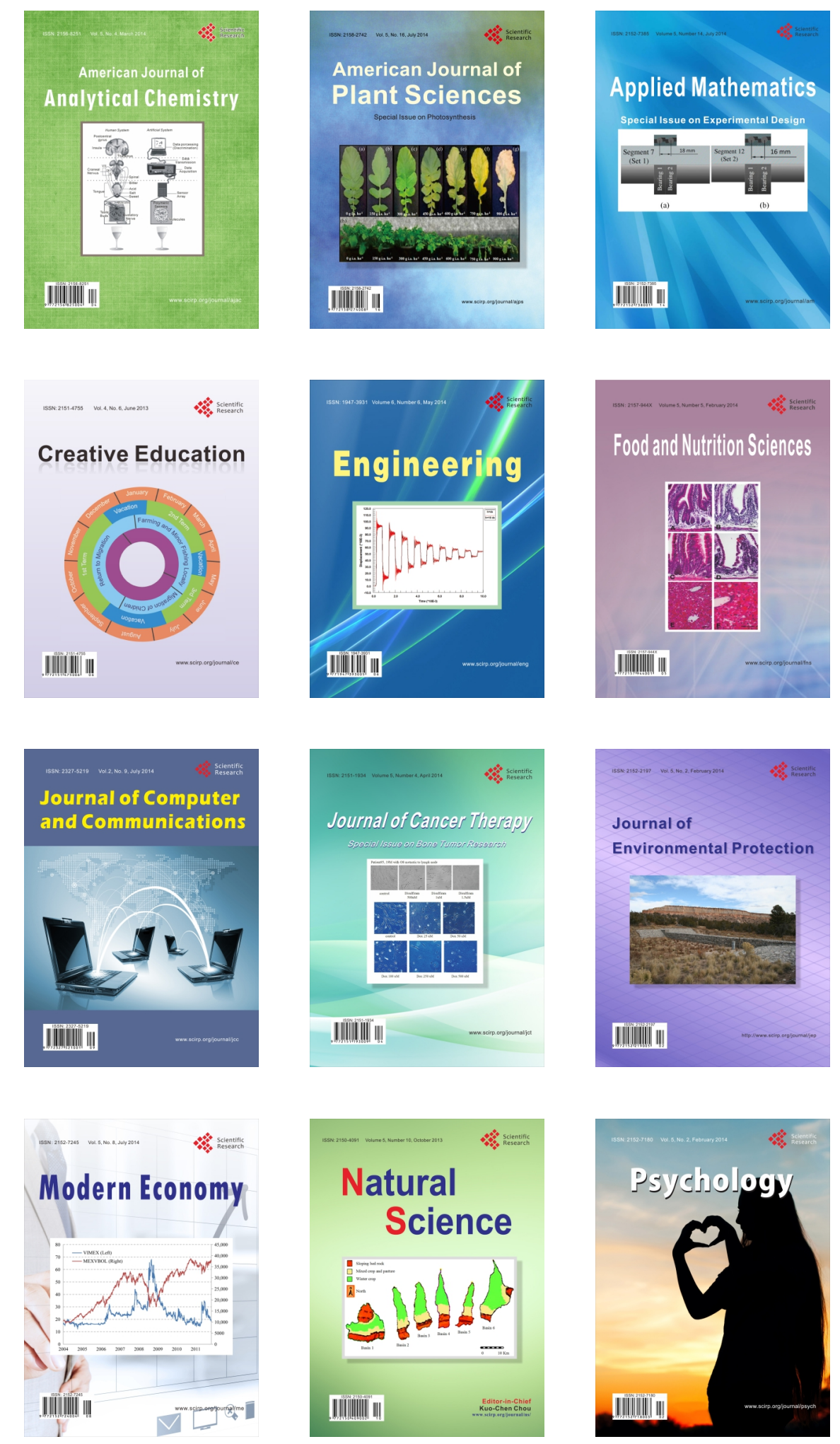